\title{
Efecto de los factores determinantes para el establecimiento de microesquejes de papaya (Carica papaya L.)
}

Jesús Arturo Ramírez Sulvarán ${ }^{2}$

Recibido:

Octubre 9 de 2009

Aceptado:

Mayo 20 de 2010
${ }^{1}$ Proyecto Financiado por el Fondo de Investigaciones Universitaria de la Universidad Francisco de Paula Santander (Cúcuta-Colombia).

${ }^{2}$ Laboratorio de Biotecnología vegetal, Universidad Francisco de Paula Santander

\section{Resumen}

El objetivo fue determinar los efectos de los factores para el establecimiento de microesquejes de papaya. Se incluyeron los efectos de los factores: 1. Protocolo de desinfección. 2. Variedad. 3. Edad de la planta donadora. 4. Número de yemas por microesquejes. 5. Los componentes hormonales en los medios de cultivo y 6. La temperatura de desarrollo de los microesquejes. Los resultados se analizaron estadísticamente mediante tablas de contingencia. También se encontró la correlación entre las variables. Los resultados indican que las mejores condiciones para el establecimiento de los microesquejes fueron: 1 . Desinfección con hipoclorito al 1,5\% durante 5 minutos. 2. La variedad de papaya Roja Melonera. 3. La edad optima de las plantas donadora fue a los 60 días. 4. Los mejor microesquejes eran los que poseía 2 yemas. 5. La relación hormonal optima fue ANA 0,1 mg/l y BAP 0,5 mg/l. 6. La temperatura de desarrollo óptima fue a $27^{\circ} \mathrm{C}$. Se concluyó que todos los factores estudiados presentaron efecto sobre el desarrollo y crecimiento de los microesquejes de papaya. De esta forma es necesario abordar estos procesos con un enfoque multifactorial.

Palabras clave: Carica papaya, microesqueje, establecimiento, multifactorial.

\section{Abstract}

Previous studies on apical and axilar microesqueje micropropagation of papaya have been lined up and without a systemic working. Consequently, it arises the actual research, which brough into study all the variables and parameters and their relationships, in order to improve the vitroplants production process, more efficiently. The main purpose of this study was to establish the effects of the former and in vitro factors, which have incidence upon the establishment of microesquejes. The effects of the former variables previous to the in vitro growing, which were studied, were: Sanitizing procedure, variety incidence, mother plant age incidence, among other ones. On the other hand, the in vitro variables studied were: temperature and hormonal compositions of the crops. 
This research was held at the vegetal biotechnology laboratory, which belongs to the biotechnology complex of the Universidad Francisco de Paula Santander in "Los Patios" Norte de Santander, Colombia. The experimental procedure was held with two months old plants from "Maradol" and "Roja Melonera" varieties. In order to accomplish the different effects of each one of the variables, it was used qualitative statistical method for their measurements. The final results showed that all factors were important to the papaya microesquejes micro propagation. As a result, the actual conclusion was to introduce the necessity to give a systemic focusing to the process in order to improve the efficiency in the vitroplants production, where all the factors and their relationships must be considered. Finally, the most important goal of this study is that all these results could be extended beyond other researches related to tropical fruits micro propagation, so important to the tropical micro propagation workers.

Key Words: Carica papaya, microcuttings, establishment, multifactors.

\section{Introducción}

$\mathrm{L}$

a papaya es una fruta importante para los pueblos de las regiones tropicales del mundo. Los métodos de propagación más empleados para esta especie son por semilla sexual y esquejes. La propagación por semilla sexual es de bajo costo, por el contrario la propagación por esquejes es muy compleja y costosa. En la actualidad existen otras alternativas para la propagación de esta especie mediante la biotecnología vegetal. La propagación de microesquejes es un método de cultivo de tejidos que tiene diversas ventajas frente el método tradicional de propagación, porque este método garantiza alta uniformidad genética de las plántulas. En correspondencia a lo anterior, existen diversos reportes de cultivos de tejidos en esta especie como Litz y Conover (1980), Drew (1988), Tovar (1989), Drew (1992), Castillo et al. (1998) Chan y Teo (2002) y Buerhing (2003). De Bruijne et al (1974) investigaron la formación de embriones a partir del cultivo de callos y Pinzón (2003) estudió la embriogénesis somática en esta especie. También existen reportes de propagación por microesquejes realizados por Litz y Conover (1978), Litz (1983), Drew y Smith (1986), Drew (1987), Rejeevan y Pandey, (1986a) entre otros. Por otra parte Drew y Smith (1989) estudiaron los factores nutricionales y hormonales en el crecimiento de los microesquejes de papaya. La mayoría de los estudio tienen un enfoque unifactorial donde no se asumen todos los factores determinantes para establecimiento de microesquejes de papaya. En este sentido, se presenta este trabajo de investigación multifactorial, el cual tiene en cuenta diversos factores para el establecimiento de los microesquejes de papaya. De esta manera, el objetivo general fue establecer un protocolo para la obtención de plántulas in vitro a partir de microesquejes de papaya (C. papaya L.)

\section{Materiales y métodos}

La investigación se efectuó en los laboratorios de biotecnología vegetal del Complejo Biotecnológico de la Universidad Francisco de Paula Santander, municipio de Los Patios, Norte de Santander-Colombia. 
En los ensayos se emplearon semilla de las variedades Maradol y Roja Melonera. Las plantas madres se obtuvieron de sembrar semillas en bolsas negras de polietileno de un $1 \mathrm{Kg}$. Las bolsas contenían una mezcla de estiércol de corral, carbón vegetal, suelo de la región y arena en proporción 2:1:1:1. A estas plantas se les aplicó riego dos veces al día. Los ensayos fueron independientes y se iban aplicando los mejores resultados en los siguientes experimentos. Todos los medio de cultivo se esterilizaron en autoclave durante 15 minutos a $121^{\circ} \mathrm{C}$ y 2 atmosfera de presión, y los frasco fueron tapados con papel aluminio. Asimismo, las condiciones de laboratorio fueron las siguientes: temperatura diurna de $27 \pm 1^{\circ} \mathrm{C}$, temperatura nocturna $24 \pm 1^{\circ} \mathrm{C}$, fotoperiodo de 16 horas luz y 8 horas oscuridad, luz con tubos fluorescente 1000 . 2000 lux de iluminación.

ENSAYO A: Efecto del protocolo de desinfección.

Los tratamientos de desinfección fueron concentraciones de hipoclorito de sodio a $1 \% ; 1,5 \% ; 2,5 \%$ y $5 \%$. El ensayo consistió en tomar esquejes de $5 \mathrm{~cm}$ de longitud de las plantas donadoras de 45 días de edad. Las plantas donadoras eran de variedad Maradol. Estos esquejes se enjuagaron en una solución jabonosa durante 5 minutos, luego fueron desinfectados con una solución de alcohol al $70 \%$ durante 5 minutos. En seguida se enjuagaron 3 veces con agua destilada estéril y se aplicaron los tratamientos anteriormente presentados durante 5 minutos cada uno. Después se enjuagaron los microesquejes con agua destilada estéril para sembrarlos en frascos con medio de cultivo esterilizado. Los medios de cultivo contenían la formulación de Murashige and Skoog (1962), adicionándole $30 \mathrm{~g}$ de sacarosa y 8 gramos de agar por litro. La relación hormonal empleada fue de ANA 0,2 mg/l, BAP 0,3. La siembra se realizó en cámara de flujo laminar siguiendo las disposiciones de asepsia convencionales. En seguida se procedió a incubarlos en cámara de crecimiento. La evaluación de los microesquejes se realizó después de 15 días de la siembra.

ENSAYO B: Efecto del la composición hormonal en los medios de cultivos para establecimiento de los microesquejes.

Los tratamientos fueron la composición y concentración hormonal del medio de cultivo. El tratamiento 1 contenía ANA 0,8 mg/l; el tratamiento 2 contenía 0,1 ANA y $0,5 \mathrm{mg} / \mathrm{l}$ de BAP 0,4, y tratamiento 3 contenía ANA 0,2 $\mathrm{mg} / \mathrm{l}$ y BAP 0,3 mg/l. La selección, el proceso de desinfección y la siembra de los explantes fueron similares al ensayo A con la variación que se empleó el mejor tratamiento del ensayo A, hipoclorito de sodio al $2 \%$.

ENSAYO C: Efecto de la variedad.

Las variedades empleadas para los tratamientos fueron la Maradol y Roja Melonera, las evaluaciones del experimento fueron a los 15, 30 y 45 días. La selección, el proceso de desinfección y la siembra de los explantes fueron similares al ensayo B. La composición de los medios fue la misma del ensayo A con la variante que se empleó la relación hormonal 0,1 ANA y 0,5 mg/l de BAP 0,4.

ENSAYO D: Efecto de edad de la planta donadora.

Los tratamientos fueron esquejes tomados de plantas donadoras de $15,30,45,60$ y 75 días de edad. La selección, el proceso de desinfección y la siembra de los explantes fueron similares al ensayo C.

ENSAYO E: Efecto del número de yemas.

Los tratamientos fueron esquejes con uno y dos yemas. La selección, el proceso de desinfección y la siembra de los explantes fueron similares al ensayo C.

ENSAYO F: Efecto de la temperatura sobre el crecimiento del microesquejes. 
Los tratamientos fueron temperaturas a $22^{\circ} \mathrm{C}, 27^{\circ} \mathrm{C}$ y $32^{\circ} \mathrm{C}$ en el día. La selección, el proceso de desinfección y la siembra de los explantes son similares al ensayo C.

\section{Resultados y discusiones}

ENSAYO A: Protocolo de desinfección.

Los resultados se presentan en la tabla 1 . Dado que el p-valor es inferior a 0,01 en el contraste de chi-cuadrado, podemos rechazar la hipótesis de que las filas y columnas son independientes con un nivel de confianza del 99\%. En consecuencia, las filas que representa la concentración de hipoclorito de sodio tienen relación con sus columnas que a su vez representa el estado de los explantes. Asimismo, la concentración de hipoclorito de sodio al 1,5\% causa poca lesión a los microesquejes por intoxicación y a su vez libera a los microesquejes de microorganismos competidores de los explantes. Esto último coincide con resultados presentados por Posada et al (2005). Sin embargo, Roca (2001) recomienda utilizar concentraciones más bajas $(0,1 \%)$ durante más tiempo (1 hora) para mejorar la relación entre la supervivencia de los ápices y la eficiencia de la desinfección. Por otra parte, las plantas donadoras deben provenir de vivero porque las plantas de campo traen más microorganismos contaminantes de los medio de cultivo. Esto último coincide con Posada et al, 2005.

Tabla 1. Resultados del efecto del tipo de protocolo de desinfección.

\begin{tabular}{|c|c|c|c|c|}
\hline $\begin{array}{c}\text { [\%] } \\
\text { Hipoclorito } \\
\text { de sodio }\end{array}$ & \multicolumn{3}{|c|}{ EXPLANTES } & Total \\
\cline { 2 - 5 } & Buenos & Muertos & $\begin{array}{c}\text { Contami- } \\
\text { nados }\end{array}$ & \\
\hline 1 & 20 & 0 & 30 & 50 \\
& $11,7 \%$ & $0,0 \%$ & $17,6 \%$ & $29,4 \%$ \\
\hline 1,5 & 26 & 7 & 7 & 40 \\
& $15,3 \%$ & $4,1 \%$ & $4,1 \%$ & $23,5 \%$ \\
\hline 2 & 26 & 6 & 8 & 40 \\
& $15,3 \%$ & $3,5 \%$ & $4,7 \%$ & $23,5 \%$ \\
\hline 5 & 8 & 32 & 0,0 & 40 \\
& $4,7 \%$ & $18,8 \%$ & $00,0 \%$ & $23,5 \%$ \\
\hline Total & 80 & 45 & 45 & 210 \\
& $47 \%$ & $26,4 \%$ & $26,4 \%$ & $99,9 \%$ \\
\hline
\end{tabular}

ENSAYO B: Composición hormonal

En la tabla 2, se presentan los resultados de este ensayo. Dado que el p-valor es inferior a 0.01, podemos rechazar la hipótesis de que las filas y columnas son independientes con un nivel de confianza del 99\%. En consecuencia, las filas tienen relación con las columnas. Por tanto, existe una correlación entre la composición hormonal y el crecimiento y desarrollo de los microesquejes para el establecimiento in vitro. Inicialmente debe señalarse que es necesario que exista un balance hormonal entre auxina y citoquinina para que haya un buen desarrollo y crecimiento de los microesquejes. El tratamiento con ANA 0,1 mg/l, BAP 0,5 mg/l desarrolló mejor los microesquejes sin producción de callo. Esto último es de interés para la micropropagación por microesquejes. Estos resultados coinciden con los presentados por Reuveni et al (1990).

Tabla 2 Resultados de efecto de la composición hormonal en los medios para el crecimiento y desarrollo de los microesquejes in vitro.

\begin{tabular}{|c|c|c|c|c|c|c|}
\hline \begin{tabular}{|c|} 
Trata- \\
mientos
\end{tabular} & $\begin{array}{l}\text { Buen } \\
\text { creci- } \\
\text { miento }\end{array}$ & $\begin{array}{l}\text { Regu- } \\
\text { lar } \\
\text { desa- } \\
\text { rrollo }\end{array}$ & $\begin{array}{l}\text { Cese } \\
\text { desa- } \\
\text { rrollo }\end{array}$ & $\begin{array}{l}\text { Desa- } \\
\text { rrollo } \\
\text { de } \\
\text { callo }\end{array}$ & $\begin{array}{c}\text { Conta- } \\
\text { minación }\end{array}$ & $\begin{array}{c}\text { Fila } \\
\text { Total }\end{array}$ \\
\hline $\begin{array}{c}\text { Medio 1 } \\
\text { ANA } \\
0,8 \mathrm{mg} / 1\end{array}$ & $\begin{array}{c}9 \\
6,9 \%\end{array}$ & $\begin{array}{c}0 \\
0,0 \%\end{array}$ & $\begin{array}{c}32 \\
24,6 \%\end{array}$ & $\begin{array}{c}9 \\
6,9 \%\end{array}$ & $\begin{array}{c}0 \\
0,0 \%\end{array}$ & \begin{tabular}{|c|}
50 \\
$38,5 \%$
\end{tabular} \\
\hline $\begin{array}{c}\text { Medio 2 } \\
\text { ANA } \\
0,1 \mathrm{mg} / 1 \\
\mathrm{BAP} \\
0,5 \mathrm{mg} / 1\end{array}$ & $\begin{array}{c}14 \\
10,8 \%\end{array}$ & $\begin{array}{c}10 \\
7,7 \%\end{array}$ & $\begin{array}{c}6 \\
4,6 \%\end{array}$ & $\begin{array}{c}1 \\
0,8 \%\end{array}$ & $\begin{array}{c}9 \\
6,9 \%\end{array}$ & $\begin{array}{c}40 \\
30,8 \%\end{array}$ \\
\hline $\begin{array}{c}\text { Medio 3 } \\
\text { ANA } \\
0,2 \mathrm{mg} / \mathrm{l}, \\
\mathrm{BAP} \\
0,3 \mathrm{mg} / \mathrm{l}\end{array}$ & $\begin{array}{c}9 \\
6,9 \%\end{array}$ & $\begin{array}{c}11 \\
8,5 \%\end{array}$ & $\begin{array}{c}8 \\
6,1 \%\end{array}$ & $\begin{array}{c}5 \\
3,8 \%\end{array}$ & $\begin{array}{c}7 \\
5,4 \%\end{array}$ & $\begin{array}{c}40 \\
30,8 \%\end{array}$ \\
\hline $\begin{array}{c}\text { Columna } \\
\text { Total }\end{array}$ & $\begin{array}{c}32 \\
24,6 \%\end{array}$ & $\begin{array}{c}21 \\
16,2 \%\end{array}$ & \begin{tabular}{|c|}
46 \\
$35,4 \%$
\end{tabular} & $\begin{array}{c}15 \\
11,5 \%\end{array}$ & $\begin{array}{c}16 \\
12,3 \%\end{array}$ & $\begin{array}{c}130 \\
100,0 \%\end{array}$ \\
\hline
\end{tabular}

\section{ENSAYO C}

Los resultados de este experimento se presentan en la tabla 3. Dado que el p-valor es inferior a 0,01, podemos rechazar la hipótesis de que las filas y columnas son independientes con un nivel de confianza del 99\%. En consecuencia, las filas tienen relación con las 
columnas. Por consiguiente podemos decir que el factor de variedad tiene un efecto sobre el crecimiento y desarrollo de los microesquejes. Los resultados señalan que los microesquejes de la variedad Roja Melonera tuvieron un mejor desarrollo frente a la variedad Maradol. Del mismo modo, se puede afirmar que existe correlación entre la edad del explante y la contaminación. Por otra parte se aprecia que en las etapas iníciales y medias del establecimiento, la supervivencia es alta pero en la etapa final aumenta drásticamente la mortalidad de los explantes esto puede ser debido a la condición de los microesquejes por los el efecto del cierre de los frascos tapados con papel de estaño o aluminio. En correspondencia a lo anterior Edwin (1993) señala que entre las desventajas del cultivo de tejidos está, el hecho de que los recipientes de plástico o vidrio cerrados inducen alta humedad relativa y poco intercambio gaseoso, esto conlleva al decaimiento del desarrollo y crecimiento de los microesquejes.

Tabla 3. Efecto del tipo de variedad.

\begin{tabular}{|c|c|c|c|c|}
\hline Tratamientos & $\begin{array}{c}\text { Desarrollo } \\
\text { Microes- } \\
\text { quejes }\end{array}$ & \begin{tabular}{|c} 
Sin \\
desarrollo \\
Microes- \\
quejes
\end{tabular} & $\begin{array}{c}\text { Explantes } \\
\text { contami- } \\
\text { nados }\end{array}$ & $\begin{array}{c}\text { Fila } \\
\text { Total }\end{array}$ \\
\hline $\begin{array}{c}10 \text { días } \\
\text { Roja } \\
\text { Melonera }\end{array}$ & $\begin{array}{c}9 \\
3,6 \%\end{array}$ & $\begin{array}{c}41 \\
16,4 \%\end{array}$ & $\begin{array}{c}0 \\
0,0 \%\end{array}$ & $\begin{array}{c}50 \\
20,0 \%\end{array}$ \\
\hline $\begin{array}{c}12 \text { días } \\
\text { Roja } \\
\text { Melonera } \\
\end{array}$ & $\begin{array}{c}24 \\
9,6 \%\end{array}$ & $\begin{array}{c}8 \\
3,2 \%\end{array}$ & $\begin{array}{c}8 \\
3,2 \%\end{array}$ & $\begin{array}{c}40 \\
16,0 \%\end{array}$ \\
\hline $\begin{array}{c}14 \text { días } \\
\text { Roja } \\
\text { Melonera } \\
\end{array}$ & $\begin{array}{c}20 \\
8,0 \%\end{array}$ & $\begin{array}{c}12 \\
4,8 \%\end{array}$ & $\begin{array}{c}8 \\
3,2 \%\end{array}$ & $\begin{array}{c}40 \\
16,0 \%\end{array}$ \\
\hline $\begin{array}{l}10 \text { días } \\
\text { Maradol }\end{array}$ & $\begin{array}{c}8 \\
3,2 \% \\
\end{array}$ & $\begin{array}{c}32 \\
12,8 \% \\
\end{array}$ & $\begin{array}{c}0 \\
0,0 \% \\
\end{array}$ & $\begin{array}{c}40 \\
16,0 \% \\
\end{array}$ \\
\hline $\begin{array}{l}12 \text { días } \\
\text { Maradol }\end{array}$ & $\begin{array}{c}22 \\
8,8 \% \\
\end{array}$ & $\begin{array}{c}11 \\
4,4 \% \\
\end{array}$ & $\begin{array}{c}7 \\
2,8 \% \\
\end{array}$ & $\begin{array}{c}40 \\
16,0 \%\end{array}$ \\
\hline $\begin{array}{l}14 \text { días } \\
\text { Maradol }\end{array}$ & $\begin{array}{c}18 \\
7,2 \%\end{array}$ & $\begin{array}{c}14 \\
5,6 \%\end{array}$ & $\begin{array}{c}8 \\
3,2 \%\end{array}$ & $\begin{array}{c}40 \\
16,0 \%\end{array}$ \\
\hline $\begin{array}{c}\text { Columna } \\
\text { Total }\end{array}$ & $\begin{array}{c}101 \\
40,4 \%\end{array}$ & $\begin{array}{c}118 \\
47,2 \%\end{array}$ & $\begin{array}{c}31 \\
12,4 \%\end{array}$ & $\begin{array}{c}250 \\
100,0 \%\end{array}$ \\
\hline
\end{tabular}

\section{ENSAYO D}

Los resultados del experimento se presentan en la tabla 4. Dado que el p-valor es inferior a 0.01 , podemos rechazar la hipótesis de que las filas y columnas son independientes con un nivel de confianza del 99\%. Por consiguiente podemos decir que el factor de edad de la planta donadora tiene un efecto sobre el crecimiento y desarrollo de los microesquejes. La edad de las plantas donadoras donde se obtuvieron mejores resultados fue a los 60 días. Estos resultados coinciden con los de Posada et al (2005).

Tabla 4. Resultados de los efectos de edad de la planta donadora

\begin{tabular}{|c|c|c|c|c|}
\hline $\begin{array}{c}\text { Tratami- } \\
\text { entos }\end{array}$ & \multicolumn{3}{|c|}{ Esquejes } & Fila \\
\cline { 2 - 4 } & $\begin{array}{c}\text { Bien } \\
\text { desarrolla- } \\
\text { dos }\end{array}$ & $\begin{array}{c}\text { Sin } \\
\text { desarrollo }\end{array}$ & $\begin{array}{c}\text { contamina- } \\
\text { dos }\end{array}$ & \\
\hline 15 días & 2 & 34 & 4 & 40 \\
& $1,0 \%$ & $17,0 \%$ & $2,0 \%$ & $20,0 \%$ \\
\hline 30 días & 4 & 30 & 6 & 40 \\
& $2,0 \%$ & $15,0 \%$ & $3,0 \%$ & $20,0 \%$ \\
\hline 45 días & 20 & 10 & 10 & 40 \\
& $10,0 \%$ & $5,0 \%$ & $5,0 \%$ & $20,0 \%$ \\
\hline 60 días & 26 & 4 & 10 & 40 \\
& $13,0 \%$ & $2,0 \%$ & $5,0 \%$ & $20,0 \%$ \\
\hline 75 días & 21 & 4 & 15 & 40 \\
& $0,5 \%$ & $2,0 \%$ & $7,5 \%$ & $20,0 \%$ \\
\hline Columna & 73 & 82 & 45 & 200 \\
Total & $36,5 \%$ & $41,0 \%$ & $22,5 \%$ & $100,0 \%$ \\
\hline
\end{tabular}

\section{ENSAYO E}

Los resultados se presentan en la tabla 5. Dado que el $p$-valor es inferior a 0.01 , podemos rechazar la hipótesis de que las filas y columnas son independientes con un nivel de confianza del 99\%. En consecuencia, las filas tienen relación con su columna. Esto significa que existe una relación directa entre el número y tamaño de explantes con el buen desarrollo de microesquejes. Los resultados indican que existen diferencias significativas cuando se utilizan diferentes números de yemas por microesquejes. Los mejores resultados fueron obtenidos con microesquejes de dos yemas. Esto posiblemente es porque las microesquejes de tamaño pequeño o de una sola yema pueden presentar lesiones que repercuten seriamente en la viabilidad del microesquejes para el establecimiento in vitro. Igualmente, el tamaño pequeño de los explantes permite que el desinfectante penetre más y por lo tanto afecte el tejido vegetal. En este ensayo 
se obtuvieron resultados de una correlación positiva entre el tamaño de los esquejes y la viabilidad in vitro. Además, es posible que el mayor tamaño presente una mayor área tisular responsable de la respuesta organogénica Dixon (1991).

Tabla 5. Resultados de efecto del efecto del tamaño.

\begin{tabular}{|c|c|c|c|c|}
\hline $\begin{array}{c}\text { Tratami- } \\
\text { entos }\end{array}$ & $\begin{array}{c}\text { Buen } \\
\text { crecimien- } \\
\text { to }\end{array}$ & Muerto & $\begin{array}{c}\text { Fila } \\
\text { Total } \\
\text { Contami- } \\
\text { nado }\end{array}$ & \\
\hline 1 & 6 & 20 & 4 & 30 \\
& $10,2 \%$ & $33,9 \%$ & $6,8 \%$ & $50,8 \%$ \\
\hline 2 & 19 & 6 & 4 & 29 \\
& $32,2 \%$ & $10,1 \%$ & $6,8 \%$ & $49,2 \%$ \\
\hline $\begin{array}{c}\text { Columna } \\
\text { Total }\end{array}$ & $\begin{array}{c}25 \\
42,4 \%\end{array}$ & $\begin{array}{c}26 \\
44,1 \%\end{array}$ & $\begin{array}{c}8 \\
13,6 \%\end{array}$ & $\begin{array}{c}59 \\
100,0 \%\end{array}$ \\
\hline
\end{tabular}

\section{ENSAYO F}

Los resultados de este ensayo se reportan en la tabla 6. Dado que el p-valor es inferior a 0.01 , podemos rechazar la hipótesis de que las filas y columnas son independientes con un nivel de confianza del 99\%. En consecuencia, las filas tienen relación con sus columnas. En este sentido la temperatura más adecuada para el desarrollo de los microesquejes es de $27^{\circ} \mathrm{C}$.

Estos resultados coinciden con los presentados por Posada et al (2005). No obstante, se observa también que el cierre de los frascos crea un sistema semicerrado que no permite la salida de vapor de agua y otros compuestos como oxígeno y el etileno al exterior del frasco, creando un sistema con una condición de alta humedad relativa que aumenta drásticamente la temperatura en el interior del frasco.

Este hecho repercute significativamente sobre el crecimiento y desarrollo de los microesquejes. Esto coincide con los resultados obtenidos por Lai et al (1998).
Tabla 6. Resultados del efecto de la temperatura.

\begin{tabular}{|c|c|c|c|c|}
\hline $\begin{array}{c}\text { Tratamien- } \\
\text { tos con tem- } \\
\text { peraturas }\end{array}$ & $\begin{array}{c}\text { Crecimien- } \\
\text { tos } \\
\text { desarrollo }\end{array}$ & $\begin{array}{c}\text { Cese } \\
\text { de } \\
\text { desarro- } \\
\text { llo }\end{array}$ & $\begin{array}{c}\text { Contami- } \\
\text { nación }\end{array}$ & Fila \\
\hline $22^{\circ}$ & 10 & 23 & 2 & 35 \\
& $9,5 \%$ & $21,9 \%$ & $1,9 \%$ & $33,3 \%$ \\
\hline $27^{\circ}$ & 24 & 7 & 4 & 35 \\
& $22,9 \%$ & $6,7 \%$ & $3,8 \%$ & $33,3 \%$ \\
\hline $32^{\circ}$ & 18 & 11 & 6 & 35 \\
& $17,1 \%$ & $10,5 \%$ & $5,7 \%$ & $33,3 \%$ \\
\hline $\begin{array}{c}\text { Columna } \\
\text { Total }\end{array}$ & 52 & 41 & 12 & 105 \\
\hline
\end{tabular}

\section{Conclusiones}

Teniendo en cuenta que todos los factores estudiados presentaron efecto sobre el desarrollo y crecimiento de los mciroesquejes de papaya es necesario abordar estos procesos con un enfoque multifactorial.

Las mejores condiciones previas para el establecimiento de microesquejes son: las plantas donadoras deben tener dos meses de edad; los microesquejes deben tener 2 yemas; la desinfección debe realizarse con hipoclorito de sodio al 1,5\% durante 5 minutos; la variedad más adecuada es la roja Melonera; la composición hormonal más eficiente es ANA 0,1 mg/l, BAP 0,5 mg/l. y la temperatura más adecuada para el desarrollo de los microesquejes es de $27^{\circ} \mathrm{C}$.

\section{Agradecimiento}

Al Fondo de Investigaciones Universitaria (FINU), de la Universidad Francisco de Paula Santander. Al Personal del laboratorio de Biotecnología Vegetal. Ing. Alina Sigarroa, Ing. Manuel Villavicencio, Ing. Leidy Contreras y Nelson Ricardo Meza.

\section{Bibliografía}

Buerhing, G (2003) Cryopreservation Studies in Carica papaya. Effect of some cryoprotectants on regrowth and somatic 
embryogenesis in Sunrise Sola papaya. In vitro Cell. Dev. Biol- Plant 39: 54-60.

Castillo, B, Smith M., Yadava U. (1998) Plant regeneration from encapsulated somatic embryos of Carica papaya L. Plant Cell Reports 17: $172-176$

Chan, L, and Teo C. (2002). Micropropagation of Eksotika, a Malaysian papaya cultivar and the field performance of the tissue culture derived clones. Acta Hort. 575: 99-105

De Bruijne E., de Langhe E. and van Rijck R. (1974). Actions of hormones and embryoid formation in callus cultures of Carica papaya. International Symposium Crop protection, Fytopharmacie en Fytiatrie. Rijkslandsbouwhooge school Medelelingen 39(6): 637-645.

Drew, R.A. (1988). Rapid clonal propagation of papaya in vitro from mature field-grown trees. HortScience 23: 609-611.

Drew, R.A. (1992) Improved techniques for in vivo propation and germoplasm storage of papaya. Hort Sci. 27:1122-1124.

Drew R. A. (1987). The effects of medium composition and cultural condicions on in vitro root anition and grow o papaya (Carica papaya L.) Journal of Horticultural Science 62, 551-6.

Drew, R. y Smith N. (1986). Grow o apical and lateral buds of papaw (Carica papaya L.) as affected by nutricional and hormone factors. Journal o Horticultural Science, 61, 535-43.

Drew, R.A. y Smith N.G. (1989). Nutricional and cultural factors affecting rooting of papaya (Carica papaya L.) in vitro Journal of Horticultural Science. 64:767-773.

Dixon, R.A. (1991). Plant Cell Culture. A Practical approach. IRL Press, Washington. $236 \mathrm{p}$.
Edwin, George. Plant propagation by tissue culture. $2^{\circ}$ Ed. Vol. 1. (1993)

Lai, Dhuo-Chu, Yu Tsong-Ann, Yeh ShyiDong And Yang Sherng (1998). Enhancement of in vitro growth of papaya multishoots by aeration.

Litz, R. E (1983) Papaya. Handbook of plant cell culture. Tropical and Subtropical fruits 2. Florida.

Litz, R. E. And Conover, R, A. (1978). In vitro propagation of papaya. HortScience, 13,241-2.

Litz, R.E. and Conover R.A. (1980). Somatic embryogenesis in cell cultures of Carica stipulate. Hortscience 15: 733- 734.

Murashige, T y Skoog, F (1962) A revised medium for rapid growth and bioassays with tabacco tissue culture by giberellin. Phisiol Plant. 15: 473 - 497

Pinzón A (2003) Embriogénesis somática y regeneración de plantas en cuatro selecciones colombianas de Carica papaya L. Resúmenes de trabajos de grado meritorios. Volumen 8 No. 1. Bogotá.

Posada L., Gómez R., Gallardo J., Reyes M. y Herrera I. (2005). Aplicaciones de la biotecnología a la propagación de la papaya. Biotecnología Vegetal Vol. 5, No. 2: 67 - 79.

Rajeevan, M. y Pandey R. (1986a). Lateral bud culture o papaya (Carica papaya L.) or clonal propagation. Plant Cell Tissue and Organ Culture, 6, 181-8.

Reuveni O, Schlesinger DR, Lavi U (1990) In vitro clonal propagation of dioecious Carica papaya. Plant Cell, Tissue and Organ Culture 20, 41-46.

Roca, W M, Mogrinski, L A (2001) Cultivo de Tejidos en la Agricultura: Fundamentos y aplicaciones. CIAT. 
Tovar, Rosalba, (2001). Estudio preliminar sobre la propagación in vitro de la lechosa (Carica papaya L.) a partir de yemas apicales y axilares. Tesis de grado. Facultad de Agronomía. U.C.V. 74 p. 